American Journal of Animal and Veterinary Sciences 2 (4): 84-88, 2007

ISSN 1557-4555

(C) 2007 Science Publications

\title{
Shed Skin of Ophiophagus hannah: Structural Topography and In Vitro Permeation of Nicotine and Phenol
}

\author{
${ }^{1}$ Priprem, A., ${ }^{1}$ Pongjanyakul, T., ${ }^{1}$ Khamlert, C., ${ }^{1}$ Chitropas, P., ${ }^{2}$ Kanla, P. and ${ }^{2}$ Sripanidkulchai, K. \\ ${ }^{1}$ Faculty of Pharmaceutical Sciences, Khon Kaen University, Khon Kaen 40002, Thailand \\ ${ }^{2}$ Faculty of Medicine, Khon Kaen University, Khon Kaen 40002, Thailand
}

\begin{abstract}
Scales of the dorsal portions of shed skin of king cobras (Ophiophagus hannah) was used as the barrier membrane for in vitro permeation of nicotine and phenol at toxic or irritable concentration levels. The scales were placed between solutions of nicotine or phenol in a donor solution at $\mathrm{pH} 5.6$ and a receptor solution at $\mathrm{pH}$ 7.4. Cumulative amounts of nicotine and phenol permeated, measured by UV-spectrophotometry which was checked by HPLC, showed a linear relationship with time $\left(\mathrm{r}^{2}>0.99\right)$, giving permeation rates of $3.76,8241.98 \mu \mathrm{g} \mathrm{cm}^{-2} \mathrm{~h}^{-1}$ and permeability coefficients of $0.38 \times 10^{-3}, 90.2 \times 10^{-3} \mathrm{~cm} \mathrm{~h}^{-1}$, respectively. Photomicrographs of the scales by scanning electron microscope (SEM) revealed 3 layers of which the innermost acting as the permeation barrier. Nicotine and phenol passed the micropits of the outer layer of the scales into the middle space where the compounds being reserved and then permeated the innermost layer of the skin. It is likely that this might be the pathway that these dose-dependent compounds were absorbed through snake skins.
\end{abstract}

Key words: Shed king cobra, nicotine, phenol and permeation

\section{INTRODUCTION}

King cobras (Ophiophagus hannah) molt periodically and repeatedly giving shed skins which behave as a barrier membrane ${ }^{[1]}$. Shed skins from different regions, dorsal and ventral or hinge and scale, of 3 species of snakes were different in surface topography and diffusion characteristics ${ }^{[2]}$. Attempts to utilize shed snake skin, a natural waste, as a membrane for drug permeation testing, were first introduced by Higuchi and Kans ${ }^{[3]}$ and followed by several others ${ }^{[1,}$ $2,4,5,6,7,8]$. Several compounds penetrated certain shed snake skins, with similar thicknesses and lipid contents to human stratum corneum, at similar rates as human stratum corneum $^{[2,9,10]}$.

Phenol and nicotine are effective snake repellant and /or toxicant ${ }^{[11]}$. Nicotine, approved by FDA as an insecticide, is a known to be present in cigarettes and used as a drug for smoking cessation therapy. It inhibits the function of acetylcholine receptors located at the neuromuscular junction; the effect is dose dependent. Phenols are environmental pollutants discharged through wastewaters from fossil refining and various industry processes. Phenol is corrosive at moderate to high concentration but effective as an antiseptic at low concentration. Both compounds possess relatively low molecular weights and degrees of ionization, as shown in Fig. 1. It was shown that the permeation of these compounds was affected by $\mathrm{pH}^{[1,12]}$, thus, it was designed to control the $\mathrm{pH}$ of donor at 5 (mimicking the skin $\mathrm{pH}$ ) and receptor at 7.4 (mimicking physiological $\mathrm{pH}$ ). This study was designed to investigate the permeation characteristics of phenol and nicotine alkaloid at toxic concentration levels through shed skin of king cobra and revealed of its structural topography.

\section{MATERIALS AND METHODS}

Materials: Nicotine was purchased from Fluka (Buchs, Switzerland); phenol from Sigma-Aldrich (Steinheim, Germany); disodium hydrogen phosphate (Fluka, Buchs, Germany); citric acid monohydrate and n-octanol (BDH Laboratory Supplies, Poole, England) and sodium phosphate (Ajax Finechem, Seven Hills, Australia). Other reagents used were analytical grade. All of the chemicals were used as received.

Shed king cobra scale: preparation and characteristics: Shed king cobra skins were collected at Khok Sanga King Cobra Club, Khon Kaen, Thailand,

Corresponding Author: A. Priprem, Faculty of Pharmaceutical Science, Khon Kaen University, Muang, Khon Kaen, 40002, Thailand. Tel/Fax: +66 43362092 
and stored in closed containers at $0 \pm 1{ }^{\circ} \mathrm{C}$. The scales from the dorsal portion of the shed skin with a diameter of larger than $1 \mathrm{~cm}$ was selected for use. The scales were cut, rinsed with distilled water and hydrated in citrate-phosphate buffer solution at $\mathrm{pH} 5.6$ (CPS) for about $12 \mathrm{~h}$ prior to use. The thickness of the dry scales of the shed skin was measured by using a microprocessor thickness gauge (Minitest 600B Typ 1210306, Cologne, Germany).

Structural topography of the scales of shed king cobra was investigated using scanning electron microscope (SEM). Cleaned shed king cobra skin was desiccated to dry stage and placed on an aluminium stup, sputter coated with gold in a vacuum evaporator and imaged using a SEM (Leo Model 1450PV SEM, England).

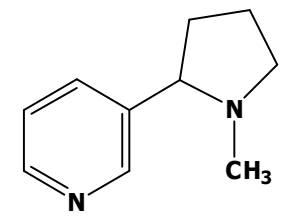

MW 162.2, $\mathrm{pK}_{\mathrm{a}} 3.04,7.84$<smiles>Oc1ccccc1</smiles>

MW 94.1, $\mathrm{pK}_{\mathrm{a}} 10.0$

Fig. 1: Structure of nicotine and phenol ${ }^{[15]}$.

In vitro permeation study: A set of 2-compartment water-jacketed side-by-side diffusion cells (Crown Glass Company Inc., U.S.A.), having a diffusion area of $0.694 \mathrm{~cm}^{2}$ and a capacity volume of $3 \mathrm{ml}$ each, was used. The donor and receptor chambers were separated by a piece of the fully hydrated scale, oriented so that the outermost surface of the scale of the shed snake skin faced the donor chamber. The interface and the two chambers was then tightly hold together using a metal clamp and fixed on the stand. The donor chamber was filled with citrate-phosphate buffer at $\mathrm{pH} 5.6$ and maintained the concentration, as follows: nicotine at 10 $\mathrm{mg} \mathrm{ml} \mathrm{m}^{-1}$ and phenol at $90 \mathrm{mg} \mathrm{ml} \mathrm{m}^{-1}$, throughout the study. The receptor chamber was filled with $3.0 \mathrm{ml}$ of

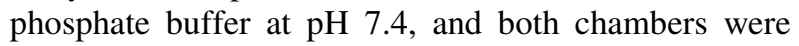
stirred $(600 \mathrm{rpm})$ to ensure adequate mixing and maintain sink conditions. The temperature of the liquids in both chambers was water-jacket maintained at
$32 \pm 0.1^{\circ} \mathrm{C}$. Samples $(2.7 \mathrm{ml})$ were taken from the receptor chambers and immediately replaced by fresh receptor solutions of equal volume. The samples were then were analyzed by UV-spectrophotometry.

Partition coefficient determination: Each compound was subjected to partition in a mixture of $n$-octanol and CPS with initial concentration at 47.38 and $2000 \mu \mathrm{g} \mathrm{ml}^{-1}$ for nicotine and phenol, $\mathrm{n}$-octanol and CPS of equal volume were pre-equilibrated for $1 \mathrm{~h}$ at a temperature of $32 \pm 1^{\circ} \mathrm{C}$. The concentration of each compound in $\mathrm{n}$-octanol and CPS layers after its equilibrium was analyzed using a UV-Visible spectrophotometer.

UV spectrophotometric analysis: Nicotine was analyzed at its $\lambda_{\max }$ of $260 \mathrm{~nm}$ using a UV-vis spectrophotometer (Shimadzu UV-1700 PharmaSpec, Japan) and phenol at $220 \mathrm{~nm}$. Standard nicotine solutions were freshly prepared at appropriate concentration ranges using the same solvents as the samples. Linear regression was used to analyze the correlation and obtain the calibration curve. Validations were performed by statistically comparisons of standards; 10 replicates of the same day and 3 replicates of different days. An reversed-phase high performance liquid chromatography (HPLC; Agilent 1100 series, Waldbronn, Germany) column (HIQ SIL $\mathrm{C}_{18}$ ) with a diameter of $4.6 \times 250 \mathrm{~mm}$ was used to confirm the stability of the permeated phenol, with UV spectrophotometry, and the system employed methanol : $0.1 \%$ phosphoric acid in deionized (DI) water (4:1) as the mobile phase, with a flow rate of $1.0 \mathrm{ml} \mathrm{min}^{-1}$ and detection at $220 \mathrm{~nm}$ by UV-detector.

Data analysis: Cumulative amounts of substances ( $Q$, $\mu \mathrm{g})$ permeating through the surface area of the scale of shed snake skin $\left(\mathrm{A}, \mathrm{cm}^{2}\right)$ were calculated and plotted against time $(\mathrm{t}, \mathrm{h})$. Linear regression analysis gave slopes with high correlation coefficients $\left(r^{2} \geq 0.99\right)$ which represented the permeation rates. Lag times were derived from the $\mathrm{x}$-intercept of the slope at steady state and the permeability coefficients $(\mathrm{P})$ were calculated according to equation $(1)^{[4]}$, as follows:

$$
P=\frac{d Q / d t}{A C d}
$$

where $d Q / d t \cdot A$ is the slope of the straight portion of the permeation curve, $A$ is the surface area $\left(0.694 \mathrm{~cm}^{2}\right)$ and $C_{d}$ is the concentration of the permeants in the donor phase. 
The diffusion coefficients, $D$, were calculated as the following equation $^{[13]}$, as follows:

$$
P=\frac{D K(o / w)}{h}
$$

where $h$ is the thickness of the scales and $\mathrm{K}_{\mathrm{o} / \mathrm{w}}$ is the partition coefficient between $n$-octanol and water of the compounds.

\section{RESULTS AND DISCUSSION}

Characteristics of shed king cobra skin: One of the main advantages of using shed skin of adult king cobras was not only that it was readily available periodically and repeatedly from the same individual but also one piece of shed skin gave about 30 pieces of scales which were sufficiently large to fit the diffusion area of the cells. The average thickness of the scales was measured to be $18.7 \pm 2.0 \mu \mathrm{m}(\mathrm{n}=25)$.

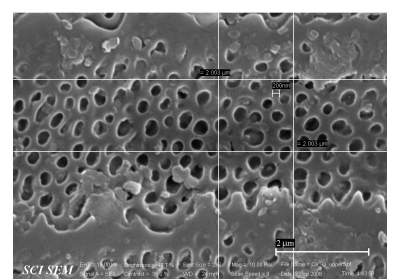

a)
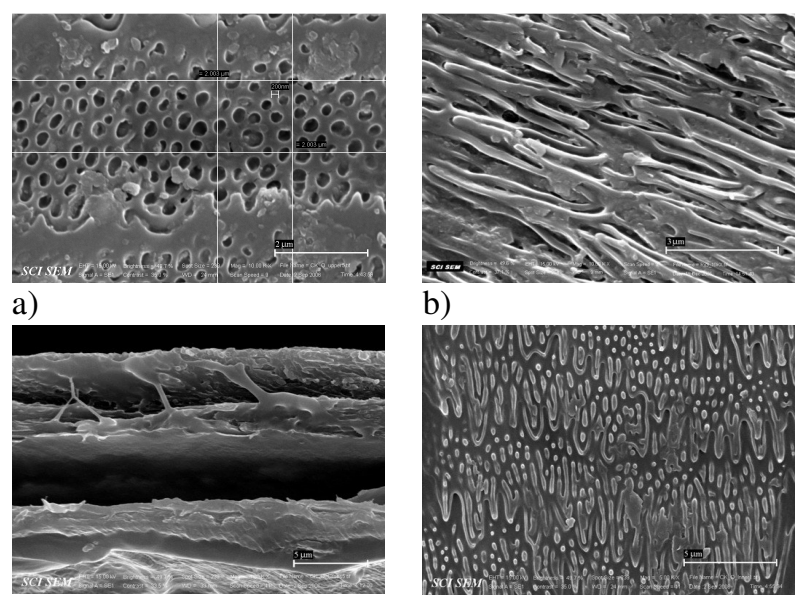

c)
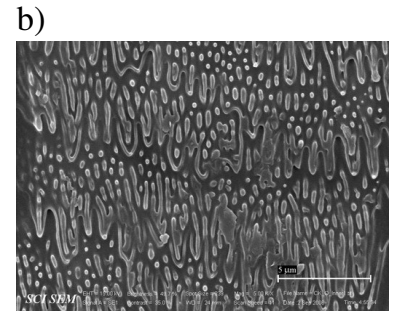

d)

Fig. 2: SEM topography of the scale of shed king cobra skin, a) middle area of the dorsal, outer surface at $10,000 \times, b)$ dorsal, outer surface at $10,000 \times, \mathrm{c}$ ) transverse section of dorsal scale at $4,000 \times$ and d) dorsal, inner surface at 5,000×.

SEM topographs of the dorsal scale of shed king cobra, shown in Fig. 2 revealed the surface and crosssection topography. Micropits, perspiration channels of other types of snakes ${ }^{[14]}$ were shown to be distributed mostly on the dorsal side. These were speculated as responsible as the delivery pores and serve to control permeability and wettability. For scales of shed king cobra skin, micropits were observed around the middle area of the dorsal scale and a diameter of as large as $200 \mathrm{~nm}$ (Fig. 2a). There were about 2 micropits per $\mu \mathrm{m}^{2}$ distributed within a defined area around the center of each scale. The other region was composed of a regular folding pattern of microfibrils (fibrous proteins) with some scattered clusters of lipid-like particles (Fig. 2b). The transverse sectional SEM photograph of the shed king cobra scale (Fig. 2c) showed 3 layers; outermost, intermediate and innermost, similar to that of $E$. obsoleta reported by Itoh et $\mathrm{al}^{[4]}$ and Takahashi et $\mathrm{al}^{[7]}$ and that of the dorsal cobra scale ${ }^{[2]}$. A space between the layers could be the reservoir of the drug solutions for further diffusion and passive transport across the innermost layer into the receptor phase. Fig. 2d illustrates the innermost region of the scale packed with fibers, where no intercellular space is observed. This is the layer which is most likely exhibiting the barrier function of the scale.

Permeation: Table shows some permeation related parameters of nicotine and phenol obtained from the experiments $(n=6)$. With a higher $\mathrm{K}_{\mathrm{o} / \mathrm{w}}$ of phenol, the permeability of phenol $\left(90 \mathrm{~cm} \mathrm{~h}^{-1}\right)$ was also higher than nicotine $\left(0.4 \mathrm{~cm} \mathrm{~h}^{-1}\right)$. There was no observed lag time for both compounds; hence, these were readily permeated without any affinity or interaction, as shown in Fig. 3a and b. Mean permeation rate of nicotine obtained was similar to that previously reported but using both the scales and hinges of king cobra shed skin $^{[1]}$ and also similar to that obtained when using porcine skin as the barrier membrane ${ }^{[12]}$. This was not in agreement with Haigh et $\mathrm{al}^{[2]}$. The permeation of these compounds through the scales of shed skin of king cobras followed Fick's first law. Nicotine, regardless of the differences in the types and regions of the skins or the $\mathrm{pH}$ conditions used. Phenol, a weak acid, gave a higher rate and extent of permeation from the study by using shed skin of Elaphe obsoleta ${ }^{[4]}$. The donor concentration of phenol in this present study was higher and kept saturated. Implication from the permeation profiles and the lethal dose of phenol suggests that phenol would rapidly and readily permeate through the skin and accumulate until reaching its lethal dose.

Phenol permeated much faster than nicotine, as shown by a higher mean flux, while the lethal dose of phenol is about 10 times higher. Furthermore, the space between layers of the snake skin could accumulate the compounds. The cumulative phenol, if any, corroded the surrounding tissue and further impaired the barrier function of the skin. The cumulative nicotine would be the depot of diffusion into the lower layers of the skin and further into the subcutaneous layer to exert its neuromuscular action. 
Table: Parameters involved in the in vitro permeation of nicotine and phenol through she king cobra scales $(\mathrm{n}=6$ each)

\begin{tabular}{lcc}
\hline Compound & Nicotine & Phenol \\
\hline Log $\left(\mathrm{K}_{\mathrm{o} / \mathrm{w}}\right)$ & $-0.83 \pm 0.05$ & $0.73 \pm 0.21$ \\
\hline $\begin{array}{l}\text { Mean flux } \\
\left(\mu \mathrm{g} \mathrm{cm}^{-2} \mathrm{~h}^{-1}\right)\end{array}$ & $3.8 \pm 1.4$ & $8242 \pm 3394$ \\
\hline $\begin{array}{l}\text { Permeability coefficient } \\
\left(\mathrm{x} 10^{-3} \mathrm{~cm} \mathrm{~h}^{-1}\right)\end{array}$ & $0.4 \pm 0.1$ & $90.2 \pm 37.2$ \\
\hline $\begin{array}{l}\text { Diffusion coefficient } \\
\left(\mathrm{cm}^{2} \mathrm{~h}^{-1}\right)\end{array}$ & $4.7 \times 10^{-6}$ & $29.2 \times 10^{-6}$ \\
\hline
\end{tabular}

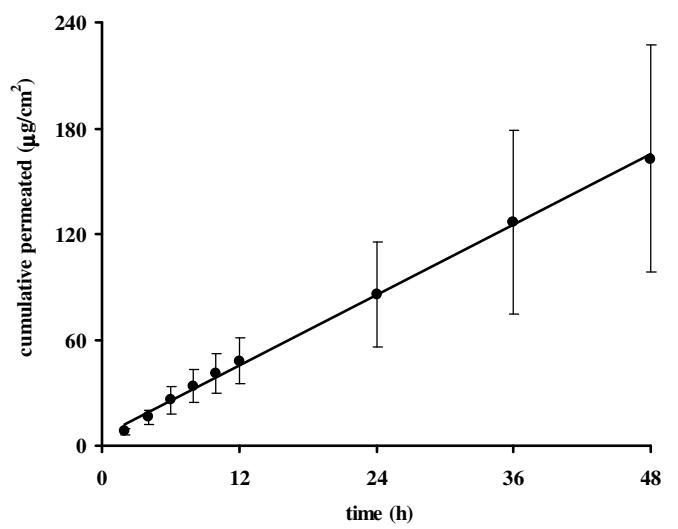

a)

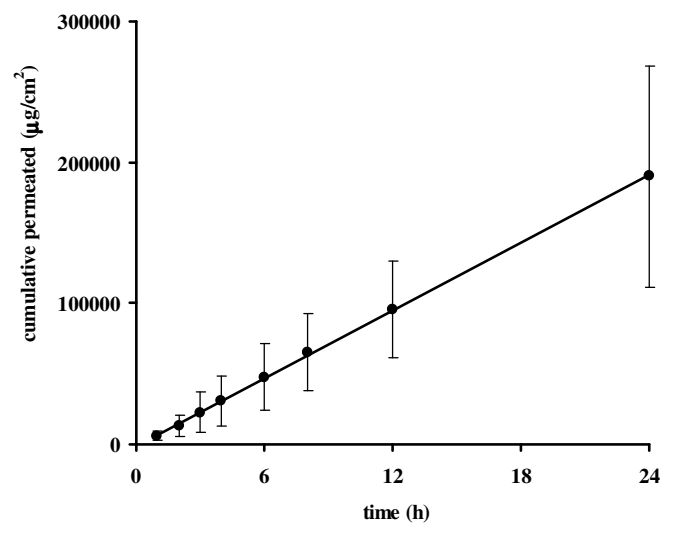

b)

Fig. 3: Time course permeation profiles of nicotine (a) and phenol (b) through scales of shed king cobra skin at $32^{\circ} \mathrm{C}$. Each point represents the mean $\pm \mathrm{SD}(n$ $=6$ each)

\section{CONCLUSIONS}

Permeation of nicotine and phenol through the shed skin of king cobra followed Fick's first law which governed by the innermost layer of the skin which behaved as the barrier membrane. The compounds could pass easily through micropits and accumulate in the void space between layers of shed skin which behaved as the reservoir. The permeation of nicotine and phenol varies according to their molecular weights, aqueous solubility and $\mathrm{K}_{\mathrm{o} / \mathrm{w}}$. The higher the molecular weight of the compounds, the slower is the permeation rate. The higher is the partition coefficient, the higher is the permeability of the compounds. The permeation of these compounds was a result of passive diffusion. The permeation was rapid and high extent through the scales and gave similar results to the whole skin. The use of shed skin provides an opportunity to perform study on toxic compounds in vitro and might imply to the permeation occurs in vivo.

\section{ACKNOWLEDGMENTS}

National Metal and Materials Technology Center (MTEC; MT-B-47-BMD-12-097-G), NSTDA; The Thailand Research Fund Master Research Grants (TRF-MAG) and the Graduate School, Khon Kaen University, are gratefully thanked for partial contributions of funds. Mr. Ta Budta and $\mathrm{Mr}$. Thongkum Chaibuddi are thanked for provision of shed king cobra skin, the Department of Biology, Faculty of Science, for SEM services and Dr. Jeff Johns, for editing of this manuscript.

\section{REFERENCES}

1. Pongjanyakul, T., S. Prakongpan, S. Panomsuk, S. Puttipipatkhachorn, and A. Priprem, 2002. Shed king cobra and cobra skins as model membranes for in vitro nicotine permeation studies. J. Pharm. Pharmacol., 54: 1345-1350.

2. Haigh, J.M., E. Beyssac, L. Chanet, and J.M. Aiache, 1998. In vitro permeation of progesterone from a gel through the shed skin of three different snake species. Int. J. Pharm., 170: 151-156.

3. Higuchi, T., and L. Kans, 1988. Method for in vitro determination of transdermal absorption. United States Patent. Patent number 4771004, 13 Sep.

4. Itoh, T., J. Xia, R. Magavi, T. Nishisata, and J.H. Rytting, 1990a. Use of shed skin as a model membrane for in vitro percutaneous penetration studies: comparison with human skin. Pharm. Res., 7: 1042-1047.

5. Bhattachar, S.N., J.H. Rytting, T. Itoh and T. Nishihata, 1992. The effects of complexation with hydrogenated phospholipid on the transport of salicylic acid, diclofenac and indomethacin across snake stratum corneum. Int. J. Pharm., 79: 263271. 
6. Harada, K., T. Murakami, E. Kawasaka, Y. Higashi, S. Yamanoyo, and N. Yata, 1993. In vitro permeability to salicylic acid of human, rodent and shed snake skin. J. Pharm. Pharmacol., 45: 414418.

7. Takahashi, K., S. Tamagawa, T. Katagi, H. Rytting, T. Nishihata, and N. Mizuno, 1993. Percutaneous permeation of basic compounds through shed snake skin as a model membrane. J. Pharm Pharmacol., 45: 882-886.

8. Ngawhirunpat, T., P. Opanasopit, and S. Prakongpan, 2004. Comparison of skin transport and metabolism of ethyl nicotinate in various species. Eur. J. Pharm. Biopharm., 58: 645-651.

9. Itoh, T., R. Magavi, R.L. Casady, T. Nishihata, and J.H. Rytting, 1990b. A method to predict the percutaneous permeability of various compounds: shed snake skin as a model membrane. Pharm. Res., 7(12): 1302-1306.

10. Rigg, C.P., and W.B. Barry, 1990. Shed snake skin and hairless mouse skin as model membranes for human skin during permeation studies. J. Invest. Dermatol., 94: 235-240.
11. Jenkins, J.H., 1962. Snake repellent. United States Patent, Patent number 3069314, 18 Dec.

12. Nair, M.K., D.J. Chetty, H. Ho, and Y.W. Chien, 1997. Biomembrane permeation of nicotine: mechanistic studies with porcine mucosae and skin. J. Pharm Sci., 86(2): 257-262.

13. Martin, A., 1993. Phyical Pharmacy. $4^{\text {th }}$ ed. United State of America: Philadelphia, London.

14. Hazel, J., M. Stone, M.S. Grace, and V.V. Tsukruk, 1999. Nanoscale design of snake skin for reptation locomotions via friction anisotropy. J. Biomechnics., 32: 477-484.

15. Moffat, A., M.D. Osselton, B. Widdop, and L.Y. Galichet, 2004. Clarke's analysis of drugs and poisons in pharmaceuticals body fluids and postmortem material. $3^{\text {rd }}$ ed. London, Pharmaceutical Press. 